\title{
URIC ACID PRODUCTION IN GOUT
}

\author{
By J. E. SEEGMILLER, ARTHUR I. GRAYZEL, LEONARD LASTER AND \\ LOIS LIDDLE
}

(From the National Institute of Arthritis and Metabolic Diseases, Bethesda, Md.)

(Submitted for publication September 20, 1960; accepted March 23, 1961)

If primary gout is an "inborn error of metabolism," as has been postulated (1), all patients might be expected to share a common, underlying defect to account for their hyperuricemia. Disagreement has centered about the problem of whether the primary derangement involves an impairment of urate disposition or an acceleration of urate biosynthesis.

In the past a variety of methods has been enployed to assess urate biosynthesis and disposition in gouty patients. The daily excretion of uric acid in the urine is a convenient parameter to measure but does not include that portion of urate production which is destroyed by uricolysis or is deposited in tophi in gouty patients. Benedict, Forsham and Stetten (2) and Bishop, Garner and Talbott (3) used uric acid- $\mathrm{N}^{15}$ to estimate the magnitude of the body urate pool and its rate of turnover. Benedict and co-workers observed that, in those gouty patients with extensive tophi and greatly expanded urate pools, such data may not provide a valid measure of urate synthesis, since uric acid from tophaceous deposits may dilute the administered isotopically labeled urate in a manner indistinguishable from that of newly synthesized uric acid. Urate biosynthesis has also been studied by measuring the extent of incorporation of an isotopically labeled precursor into urinary uric acid. Some, though not all, of the gouty subjects studied were found to incorporate excessive amounts of glycine- $\mathrm{N}^{15}$ into urinary uric acid (4, $5)$. When trace amounts of glycine-1-C $\mathrm{C}^{14}$ were used in similar studies, an excessive incorporation of isotope into urinary uric acid was found in all of the six gouty subjects first investigated (6), but subsequent studies showed that there were some gouty patients in whom excessive incorporation of glycine-1-C $\mathrm{C}^{14}$ into uric acid could not be detected (7-9). An excessive production of uric acid could exist in such gouty patients, yet fail to be reflected in the extent of glycine incorporation into urinary uric acid because of enhanced extra- renal disposal of urate through deposition in tophi or increased uricolysis

The purpose of the present investigation was to evaluate urate production in gouty subjects in a manner that would allow corrections to be made for the extra-renal disposal of urate. Studies were performed with isotopically labeled glycine to evaluate purine synthesis and isotopically labeled uric acid to evaluate the dynamics of the urate pool. The determination of the urate pool turnover provided an independent estimate of uric acid biosynthesis. The results obtained were correlated with clinical features of the disease and with urinary excretion of uric acid. On the basis of these studies, some conclusions were drawn regarding the relative roles of excessive urate production and impaired urate disposition in the pathogenesis of the hyperuricemia of gout.

\section{METHODS}

Subjects. All normal control subjects were males, ranging in age from 23 to 65 years. They were predominantly young, healthy volunteers, but several older

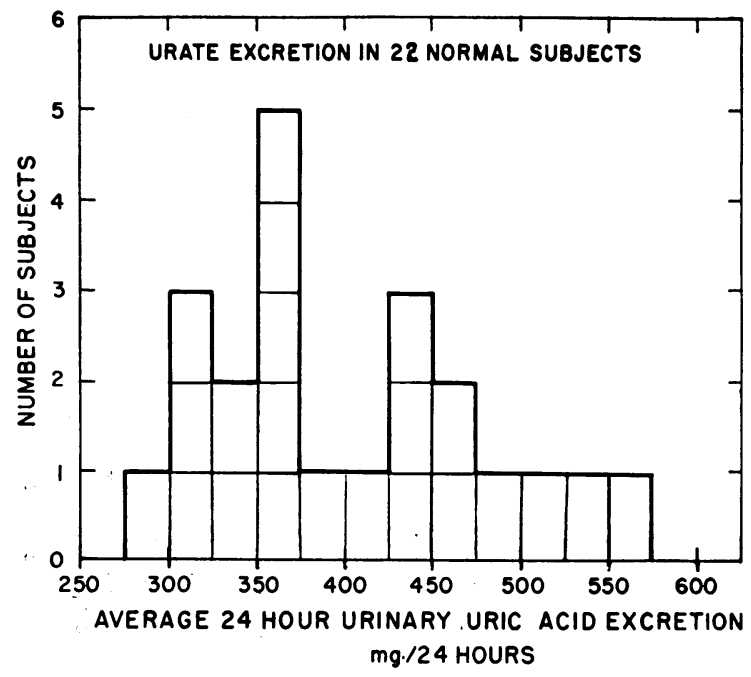

Fig. 1. The 3-DAy AVERage 24-hour URINARy URIC ACID EXCRETION OF NORMAL MALES ON A PURINE-FREE DIET. 


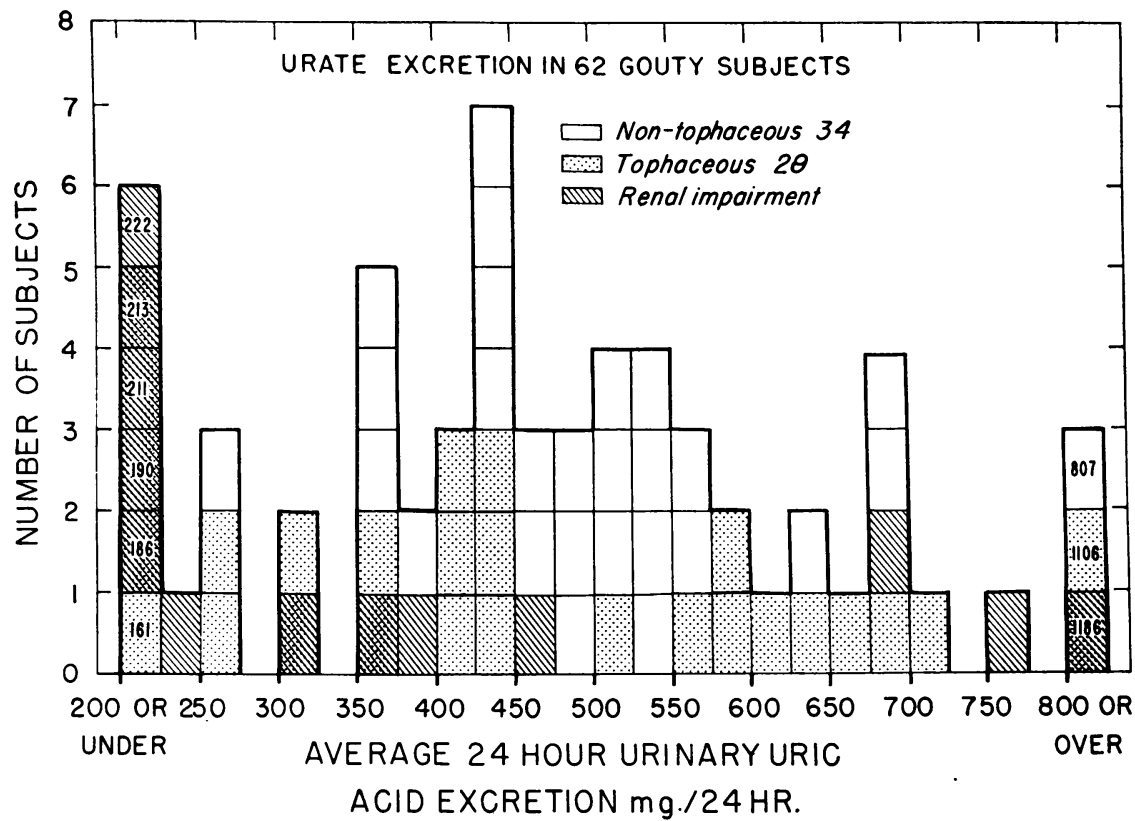

Fig. 2. The 3-DAy AVERAge 24-hour URINARY URIC ACID EXCRETION OF GOUTY MALES ON A PURINE-FREE DIET.

subjects with mild degenerative osteoarthritis were included. Renal function, as assessed by routine urine analysis, blood urea nitrogen levels and the phenolsulfonphthalein (PSP) excretion test, was unimpaired in all control subjects and in none was there a family history of gout.

All the gouty subjects had experienced several attacks of acute arthritis that had responded to colchicine. Their serum urate values were definitely within the hyperuricemic range. All patients who were studied with isotopically labeled glycine had suffered attacks typical of acute gouty arthritis which responded to colchicine while under our care. Renal impairment was considered present when the blood urea nitrogen was more than $22 \mathrm{mg}$ per $100 \mathrm{ml}$ or the PSP test revealed less than 45 per cent of the dye to have been excreted in 2 hours, or both.

All studies were performed on gouty and normal subjects during hospitalization. They were maintained on a standard 2,600 calorie diet essentially free of purines, containing $70 \mathrm{~g}$ protein, $350 \mathrm{~g}$ carbohydrate and $100 \mathrm{~g}$ fat. At least 5 days was allowed for equilibration on the diet before studies were begun. No patients received medications other than colchicine, and this was omitted during the day prior to and for the 3 days after administration of isotopically labeled compounds. Most patients with tophaceous gout had received some form of uricosuric therapy for varying periods of time prior to hospitalization.

Materials. Glycine- $\mathrm{N}^{15}$ was synthesized as previously described $(10,11)$ with an isotope abundance ranging from 58.8 to 62.7 atom per cent excess for different batches of glycine. Uric acid-2- $\mathrm{C}^{\mathbf{1 4}}$ was synthesized from urea-C ${ }^{14}$ (obtained from Tracerlab, Inc., Boston) by the method of Cavalieri, Blair and Brown (12). The synthetic product was purified by recrystallization and its purity and identity established by reaction with uricase (13). The ultraviolet absorption spectrum showed an extinction coefficient, $\epsilon_{292}$, of 12,790 . The synthesized uric acid was diluted with carrier to give a specific activity of $12.1 \mu \mathrm{c}$ per mmole. Uric acid-1,3- $\mathrm{N}^{15}$, containing 28.6 atom per cent excess of $\mathrm{N}^{15}$, was kindly provided by Miss Jean Benedict. Samples of uric acid for intravenous injection were sterilized by millipore filtration

TABLE I

Changes in serum urate levels induced by a purine-free diet

\begin{tabular}{|c|c|c|c|c|c|}
\hline \multirow[b]{2}{*}{ Patients } & \multirow[b]{2}{*}{ No. } & \multicolumn{2}{|c|}{ Before diet } & \multicolumn{2}{|c|}{ On diet for 7 days } \\
\hline & & $\begin{array}{c}\text { Mean serum } \\
\text { urate level }\end{array}$ & $\mathrm{SD}$ & $\begin{array}{c}\text { Mean serum } \\
\text { urate level }\end{array}$ & SD \\
\hline & & $m g \%$ & & $m g \%$ & \\
\hline Normal & 22 & 5.32 & \pm 0.93 & 4.69 & \pm 0.68 \\
\hline Gouty & 60 & 9.45 & \pm 1.88 & 8.44 & \pm 1.92 \\
\hline
\end{tabular}




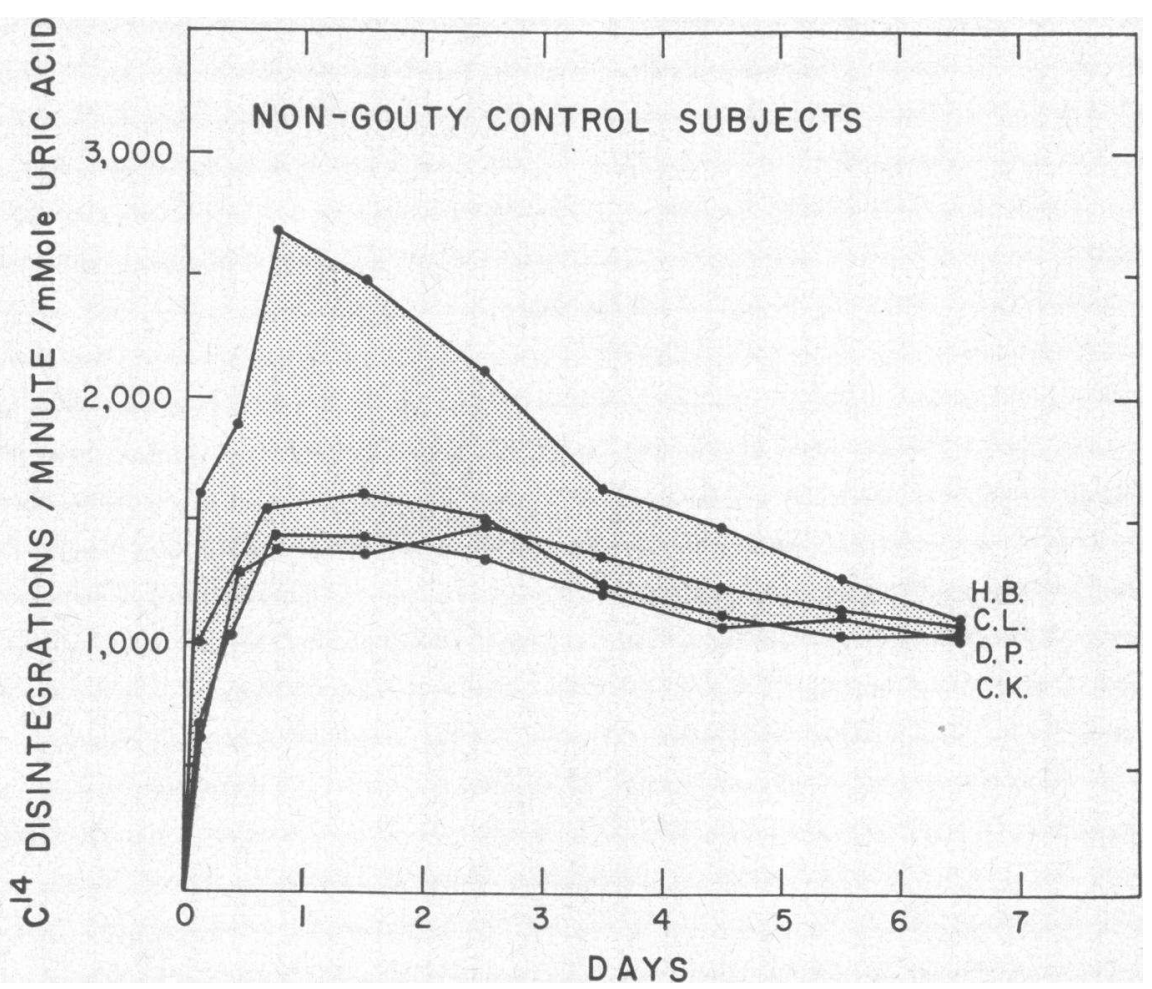

Fig. 3. THE SPECIFIC ACTIVITY OF URINARY URIC ACID IN NORMAL SUBJECTS AFTER THE ORAL ADMINISTRATION OF $5 \mu \mathrm{C}$ OF GLYCINE-1-C ${ }^{14}$.

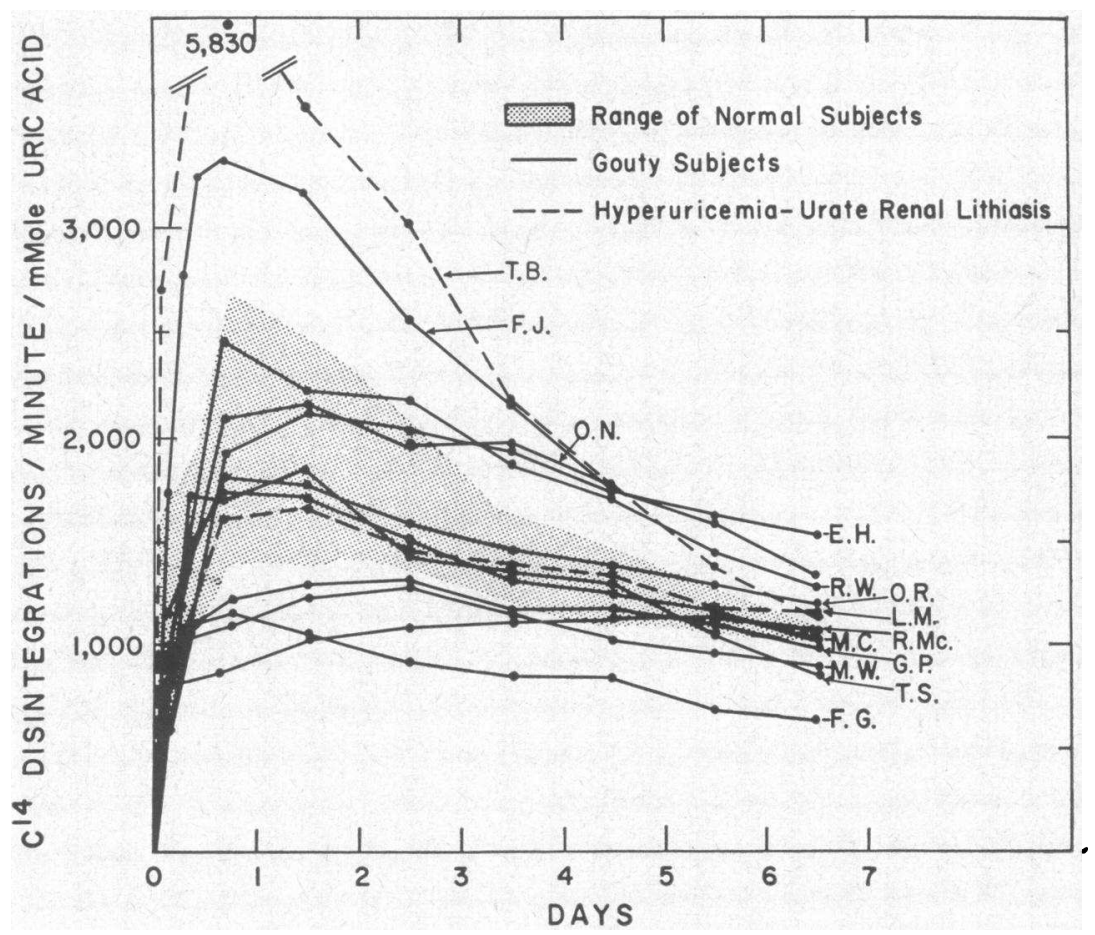

Fig. 4. THE SPECIFIC ACTIVITY OF URINARY URIC ACID IN GOUTY SUBJECTS AFTER THE ORAL ADMINISTRATION OF GLYCINE-1-C ${ }^{14}$. 
TABLE II

Incorporation of isotopically labeled uric acid and glycine into urinary uric acid

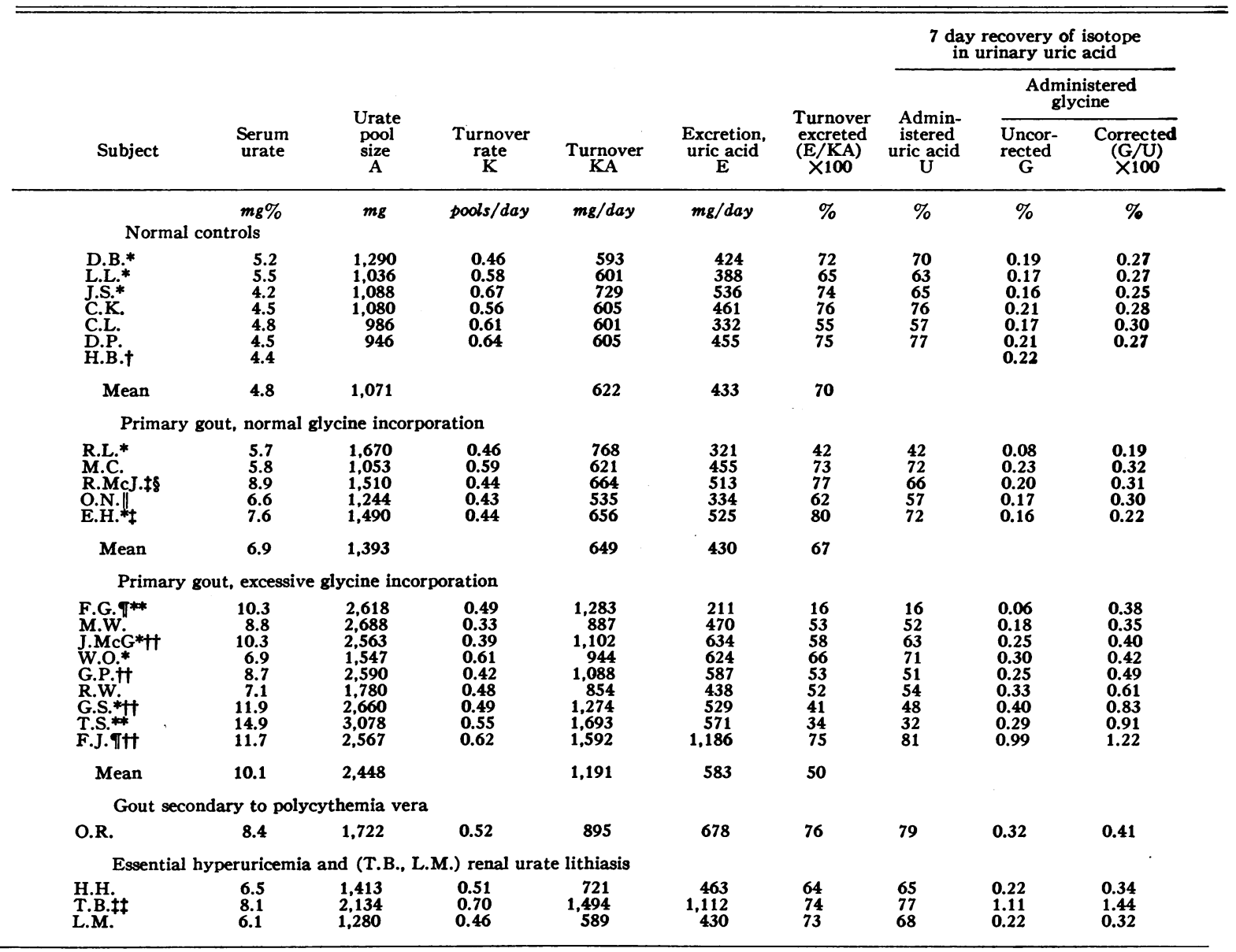

* Patients who received glycine- $\mathrm{N}^{16}$ and uric acid-2-C ${ }^{14}$; the remainder received glycine-1-C14 and uric acid- $\mathrm{N}^{15}$.

$t$ No uric acid- $\mathrm{N}^{15}$ administered.

Minimal tophaceous involvement, X-ray evidence only.

Patient R.McJ. developed evidence of polycythemia vera 2 years after this study.

Five day incorporation.

Diminished PSP excretion, less than $45 \%$ of the injected dye excreted in 2 hours

** Severe tophaceous involvement.

\# Patient T.B. is reported by his personal physician to have had one episode of acute arthritis since this study was performed.

of the lithium salt in 5 per cent glucose solution. Glycine-1-C $\mathrm{C}^{14}$ with a specific activity of $1.33 \mathrm{mc}$ per mmole was obtained from Tracerlab of Boston. Hippuric acid (benzoyl glycine-1-C ${ }^{14}$ ), for preparing the self-absorption curve of this compound, was obtained from NuclearChicago. Creatine-1-C $\mathrm{C}^{\mathbf{4}}$, obtained from Volk RadioChemical Company, was converted to creatinine by heating for 1 hour in an autoclave at 15 pounds' pressure in $0.5 \mathrm{HCl}$ and isolated as the double salt of zinc chloride (14) for preparation of a self-absorption curve.

Studies. Studies performed with isotopically labeled compounds were of two types: 1) patients received 0.72 $\mu \mathrm{c}$ of uric acid-2-C $\mathrm{C}^{14}$ intravenously, and at the same time, $100 \mathrm{mg}$ per $\mathrm{kg}$ of glycine- $\mathrm{N}^{\mathrm{1s}}$ orally with their breakfast milk; 2) other patients received $36 \mathrm{mg}$ of uric acid- $\mathrm{N}^{15}$ intravenously and $5 \mu \mathrm{c}$ of glycine-1-C $\mathrm{C}^{14}$ orally with their breakfast milk. Sodium benzoate was administered to sample the glycine pool contributing to the synthesis of hippuric acid, as previously described (15).

Analytical and isolation procedures, as well as the procedures for determining the radioactivity and $\mathrm{N}^{15}$ content of samples, were performed as previously described (15). Calculations of the body urate pool and turnover were identical with those of Benedict and colleagues (2).

\section{RESULTS}

Urinary uric acid and serum urate values on a standard diet. The range of values obtained for the daily urinary uric acid excretion of a group of normal and gouty males under careful dietary control is shown in Figures 1 and 2. The 22 normal males showed a mean value of $426 \mathrm{mg}$ per day 
$(\mathrm{SD} \pm 81 \mathrm{mg})$. Assuming a normal distribution of values, less than 3 per cent of such a population would be expected to excrete more than $600 \mathrm{mg}$ per day. This value was taken as the upper limit of normal. The mean values for 62 gouty patients was $480 \mathrm{mg}$ per day, which was within $1 \mathrm{SD}$ of the normal mean. The gouty patients (Figure 2) showed a much wider range of values than did the normal subjects. Thirteen patients (21 per cent) excreted more than $600 \mathrm{mg}$ of uric acid in their urine per day, while a substantial number, especially those with renal damage, excreted abnormally small amounts.

The effect on serum urate values of ingesting a purine-free diet for 1 week is shown in Table I. The values obtained after 5 days of the diet did not differ substantially from values obtained after 7 days or longer. An equilibration period of 5 days was therefore regarded as adequate preparation for isotope incorporation study.
Incorporation of isotopically labeled glycine into uric acid. The specific activity of $\mathrm{C}^{14}$ in urinary uric acid after the administration of glycine-1- $\mathrm{C}^{14}$ has previously been used (6) as an index of uric acid production. The range of values obtained in studies of nongouty control subjects shown in Figure 3 is superimposed upon values obtained in gouty subjects in Figure 4. The only patients who showed higher than normal values for specific activity (F.J. and T.B.) also excreted abnormally large amounts of uric acid daily in their urine. This relationship has been noted by others in experiments with glycine- $\mathrm{N}^{15}(4,9,16)$ as well as in experiments with glycine-1- $\mathrm{C}^{14}(9)$.

The cumulative recovery of isotope in urinary uric acid during a given period of time after the administration of isotopically labeled glycine may be an even better index of uric acid production than the specific activities shown in Figure 4 (6). Such cumulative incorporation values obtained in

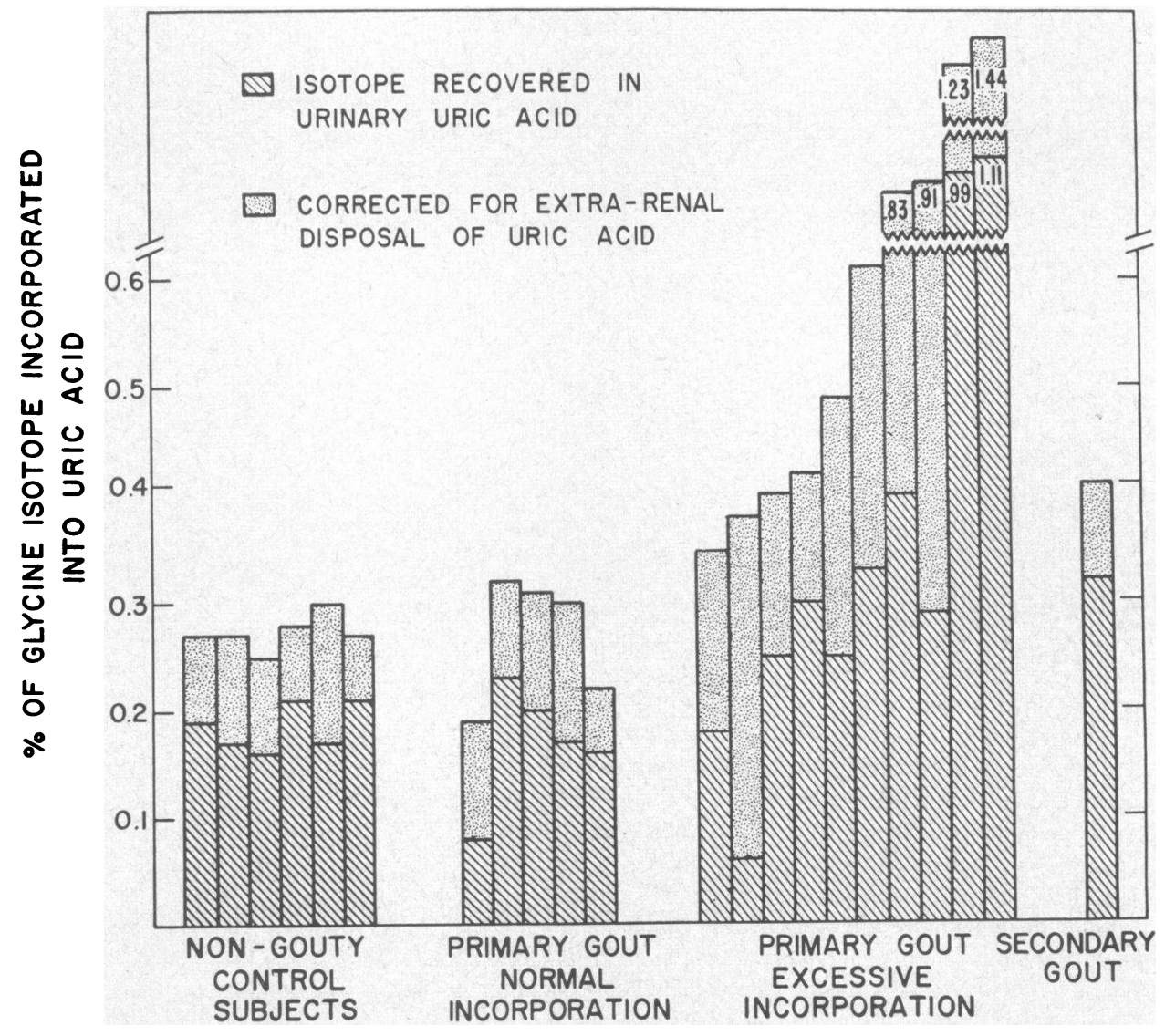

Fig. 5. INCORPoration OF ISOTOPICALly LABELED GLYCINE INTO URINARY URIC ACID IN CONTROL AND GOUTY SUBJECTS AND THE MAGNITUDE OF THE CORRECTION FOR THE EXTRA-RENAL DISPOSAL OF URIC ACID. See Table II for details of study. 
the present studies are presented in column $G$ of Table II and in Figure 5. The very low values obtained for R.L. and F.G. raised the possibility that these subjects might be disposing of a considerable portion of their daily uric acid production by means other than renal excretion, thus lowering the amount of isotope that could be recovered in their urinary uric acid. To determine the fraction of newly formed uric acid that failed to appear in the urine, isotopically labeled urate was injected intravenously. This labeled uric acid shared the same fate as urate synthesized by the body, hence the percentage of isotopically labeled urate that was recovered in the urine equaled the fraction of newly synthesized urate that was excreted. The percentage of administered isotopically labeled uric acid recovered in the urine in 7 days is shown in column $U$. By the seventh day, the abundance in urinary uric acid of the isotope from the administered urate had declined to 3 per cent or less of the peak value, except in M.W. and O.W., in whom this value was 5 per cent. When these urate recovery values (column $U$ ) were used to correct the cumulative glycine incorporation values (column $G$ ) for the fraction of the uric acid which failed to appear in the urine, the resulting corrected values (last column) represented the best approximation of the amount of isotope from glycine that was delivered to the body's urate pool. The correction for extra-renal disposal of uric acid is applicable to experiments in which either $\mathrm{N}^{15}$ or $\mathrm{C}^{14}$ was used as a label for glycine.

Table II includes data obtained from studies in which glycine- $\mathrm{N}^{15}$ or glycine-1- $\mathrm{C}^{14}$ was used. The two isotopes do not result in identical labeling of the uric acid molecule and therefore cannot always be strictly compared. The fact, however, that there were gouty subjects who showed glycine incorporation values within the same range as nongouty control subjects, whether studies were carried out with glycine- $\mathrm{N}^{15}$ or with glycine-1- $\mathrm{C}^{14}$, is evidence that such normal glycine incorporation values are not an artifact of the method of study.

\section{DISCUSSION}

Corrected glycine incorporation into uric acid as an index of urate biosynthesis. The extent of incorporation of isotopically labeled glycine into urinary uric acid is a very sensitive index of urate biosynthesis when corrected for the newly synthesized uric acid that fails to appear in the urine because of extra-renal disposal. In the present study, allowance was made for this correction in determining urate biosynthesis in gouty patients. That the amount of uric acid disposed of by routes other than renal execretion can be sufficiently great as to completely mask the increased uric acid production of some gouty patients, is shown in Table II. The data in column G indicate that the increased glycine incorporation of $\mathrm{Pa}$ tients F.G., M.W. and G.P. would have gone undetected unless corrections for the extra-renal disposition of urate were made. In Patients F.G. and G.P. the presence of tophaceous involvement probably accounts for the large extra-renal disposition of urate. Although J.McG., G.S., T.S. and F.J. also had tophi, their uncorrected values (column G) fell in the overproducer class. In these instances correction for the extra-renal disposition of urate served to accentuate the difference between these patients and the controls. Even in the absence of tophaceous involvement the correction is of substantial proportions (R.L. and M.W.) and can affect the interpretation of data. The influence of the correction is shown graphically in Figure 5. Since the magnitude of this correction varies considerably, even among normal control subjects (Table II, column U), a consideration of such a correction in all subjects seems warranted. Nine of 14 patients with primary gout reported here had corrected glycine incorporation values (Table II, last column) above the range found in control subjects and were regarded as overproducers of uric acid.

More significant, however, is the fact that there remained five gouty patients who gave no evidence of an increased uric acid production even when their extra-renal disposition of urate was taken into account. The corrected glycine incorporation values of these five patients were in the same range as the nongouty subjects, whether glycine- $\mathrm{N}^{15}$ or glycine-1-C ${ }^{14}$ was used. This group of patients had lower serum urate levels, less tophaceous involvement, smaller body urate pools and turnover, and lower 24-hour urinary uric acid excretion values than did the group of overproducers (Table II). As noted previously, each of these five patients had suffered repeated attacks of acute gouty arthritis that had responded 
to colchicine during previous hospitalizations under our care. Although the serum urate levels of gouty patients R.L. and M.C. were within the normal range during the studies here reported, values of 7.8 and $7.9 \mathrm{mg}$ per $100 \mathrm{ml}$, respectively, were obtained on other occasions while they were not on a purine-free diet. Similarly, Patients H.H. and L.M., with essential hyperuricemia, showed serum urate values of 8.1 and $6.8 \mathrm{mg}$ per $100 \mathrm{ml}$ while not on a purine-free diet. The normal size of the urate pool in M.C. and O.N. is attributed to their low serum urate levels and the absence of tophi.

Some of the uncorrected values for glycine incorporation into uric acid (column G, Table II) obtained in studies of nongouty control subjects are slightly higher than values reported for control subjects in other studies. With glycine- $\mathrm{N}^{15}$, values of 0.10 to 0.15 have been reported $(4,9$, 11 ), while values of 0.11 to 0.18 have been published for studies in which glycine-1- $\mathrm{C}^{14}$ was used $(6,9)$. The value of 0.17 obtained in this study for Patient C.L. is in good agreement with the value of 0.18 obtained in a comparable study of this same subject by another investigator (6). It seems that nongouty subjects vary considerably in the extent to which they incorporate glycine into uric acid. This variation is in part a reflection of the variable degree to which normal subjects dispose of uric acid by means other than renal excretion (Table II, column U).

Urate turnover values as an index of urate biosynthesis. An independent measure of uric acid production is provided by the urate turnover values (column KA, Table II). Urate turnover values within the range of normal were found in those gouty patients with normal glycine incorporation values, thus offering confirmatory evidence that uric acid production was normal in these patients. Errors in the urate turnover values, as noted by Benedict and co-workers (17), result from the presence of easily miscible urate in the solid phase. The resulting error gives rise to turnover values in excess of actual uric acid production. Since the turnover values found in the present study of these five patients were normal rather than elevated, they can be regarded as valid indices of uric acid production. Further evidence of the validity of the calculation of the urate pool size and turnover values is provided by the good agreement (Table II) between the percentage of turnover excreted [ $(\mathrm{E} / \mathrm{KA}) \times 100]$ and the recovery of administered isotopically labeled uric acid (column $U$ ). The absence of solid phase miscible urate in this group of patients with normal urate turnover values was confirmed by using the calculations described by Benedict and coworkers.

Variation of uric acid production among gouty patients. The magnitude of production of uric acid among gouty subjects varied greatly from one patient to another. In some patients overproduction was sufficiently great as to be reflected in their daily output of urinary uric acid which was up to two to three times greater than normal. From this extreme, the degree of overproduction ranged downward to patients in whom very modest increases were detectable only by the use of isotopically labeled compounds (Table II, column KA and last column). The separation of the latter patients from gouty patients who produce normal amounts of uric acid was quite arbitrary, and it is probable that more studies would show complete merging of values for the two groups.

Uric acid production in relation to the natural history of gout. The question as to whether excessive production of uric acid is a characteristic of a given patient or merely represents a stage in the evolution of the disease, cannot be answered conclusively, although the evidence now available tends to support the former view. There seems to be no correlation between the amount of uric acid produced and the duration of the disease. Furthermore, in Patient T.B., with hyperuricemia and urate renal lithiasis, excessive uric acid production was present for several years before the first attack of acute gouty arthritis occurred. In addition, Patients T.S. and F.G., who showed comparable degrees of extreme tophaceous involvement, differed greatly in the extent of their glycine incorporation.

Repeat studies performed on some patients gave more direct support for the view that the degree of production of uric acid is, in most cases, a characteristic of the individual patient. The daily urinary excretion of uric acid in Patients T.B. and F.J. remained near $1,100 \mathrm{mg}$ per day during several hospitalizations over the course of 3 years, while Patients M.C., O.N. and R.L. continued to have low excretion values during the same 
time. Repeat studies with isotopically labeled compounds were performed in a few patients. In a second study, 20 months after the first, Patient M.C. had a urate turnover of $554 \mathrm{mg}$ per day and a corrected glycine-1-C $\mathrm{C}^{14}$ incorporation value of 0.33 per cent, in excellent agreement with the earlier study. After 46 months with the uricosuric agents, the urate turnover value of $\mathrm{Pa}$ tient J. McG. decreased from 1,102 to $766 \mathrm{mg}$ per day. However, the corrected value for glycine1-C ${ }^{14}$ incorporation was 0.43 per cent, compared with the previous value of 0.40 per cent obtained with glycine- $\mathrm{N}^{15}$. That the extent of urate production may sometimes be familial is suggested by the fact that Patient F.J. has two gouty brothers whose daily urinary uric acid excretion also averaged approximately $1,100 \mathrm{mg}$ per day, providing evidence that all three brothers produced excessive amounts of uric acid.

An anomalous result was obtained in a second study of Patient E.H. In this study the corrected glycine-1-C 14 incorporation was 0.46 per cent compared with a corrected glycine- $\mathrm{N}^{15}$ incorporation of 0.22 per cent found 28 months earlier. The fact that the urate turnover value in the second study was unchanged (652 mg per day as com- pared with $661 \mathrm{mg}$ per day) is evidence against occurrence of a true change in uric acid production, since turnover values within this range are not subject to the errors previously discussed. A difference in his metabolism of the trace dose of glycine-1- $\mathrm{C}^{14}$, as compared with the larger dose $\left(0.1 \mathrm{~g}\right.$ per $\mathrm{kg}$ ) of glycine- $\mathrm{N}^{15}$, may have contributed to the disparate glycine incorporation values observed in this patient $(6,9)$. The studies of glycine incorporation into compounds other than uric acid (see below) may be relevant to this problem.

Other examples of an excessive incorporation of glycine-1- $\mathrm{C}^{14}$ into urinary uric acid in the presence of a normal production of uric acid have been noted and possible explanations have been proposed $(6,18)$. Evidently, glycine incorporation alone may not always provide a valid index of the magnitude of uric acid synthesis.

Glycine incorporation into urinary creatinine and hippuric acid. There are many pathways for glycine metabolism and several metabolically distinct pools of glycine in man $(19,20)$. An altered disposition of glycine in the gouty individual could conceivably result in the availability of a larger amount of glycine for purine synthesis. Although

TABLE III

Incorporation of glycine-1-C 14 into urinary creatinine and hippuric acid

\begin{tabular}{|c|c|c|c|c|c|c|}
\hline \multirow[b]{2}{*}{ Subjects } & \multirow{2}{*}{$\begin{array}{l}\text { Incorporation } \\
\text { into urinary } \\
\text { creatinine } \\
\text { in } 7 \text { days }\end{array}$} & \multicolumn{5}{|c|}{ Day } \\
\hline & & 1 & 2 & 3 & 5 & 7 \\
\hline \multicolumn{2}{|c|}{ Normal } & \multicolumn{4}{|c|}{$d p m / m m o l e ~ h i p p u r i c$ acid isolated } & \\
\hline $\begin{array}{l}\text { H.B. } \\
\text { C.K. } \\
\text { C.L. } \\
\text { D.P. }\end{array}$ & $\begin{array}{l}0.31 \\
0.46 \\
0.32 \\
0.56\end{array}$ & $\begin{array}{r}10,544 \\
9,028 \\
15,499\end{array}$ & $\begin{array}{l}1,961 \\
3,031 \\
2,899 \\
2,533\end{array}$ & $\begin{array}{r}839 \\
1,286 \\
1,257 \\
1,216\end{array}$ & $\begin{array}{l}404 \\
643 \\
896 \\
704\end{array}$ & $\begin{array}{l}322 \\
423 \\
441 \\
485\end{array}$ \\
\hline \multicolumn{7}{|c|}{ Primary gout } \\
\hline $\begin{array}{l}\text { M.C. } \\
\text { R.McJ. } \\
\text { E.H. } \\
\text { F.G. } \\
\text { M.W. } \\
\text { J.McG. } \\
\text { G.P. } \\
\text { T.S. } \\
\text { F.J. }\end{array}$ & $\begin{array}{l}0.28 \\
0.46 \\
0.30 \\
0.20 \\
\\
\\
0.44 \\
0.19 \\
0.64\end{array}$ & $\begin{array}{r}13,932 \\
7,178 \\
18,867 \\
15,598 \\
9,953 \\
9,413 \\
10,716 \\
11,286\end{array}$ & $\begin{array}{l}2,342 \\
3,674 \\
2,435 \\
2,657 \\
2,132 \\
2,442 \\
1,860 \\
2,637 \\
3,109\end{array}$ & $\begin{array}{r}1,138 \\
1,004 \\
1,131 \\
1,245 \\
1,069 \\
1,287 \\
824 \\
1,759 \\
1,661\end{array}$ & $\begin{array}{l}649 \\
617 \\
709 \\
810 \\
679 \\
\\
630 \\
944 \\
753\end{array}$ & $\begin{array}{l}481 \\
456 \\
663 \\
662 \\
447 \\
598 \\
435 \\
\\
605\end{array}$ \\
\hline \multicolumn{7}{|c|}{ Secondary gout } \\
\hline O.R. & 0.33 & 20,930 & & 1,892 & 873 & 644 \\
\hline \multicolumn{7}{|c|}{ Essential hyperuricemia and renal urate lithiasis } \\
\hline $\begin{array}{l}\text { T.B. } \\
\text { L.M. }\end{array}$ & $\begin{array}{l}0.64 \\
0.28\end{array}$ & $\begin{array}{l}11,936 \\
12,879\end{array}$ & 2,490 & $\begin{array}{l}1,306 \\
1,170\end{array}$ & $\begin{array}{l}690 \\
641\end{array}$ & $\begin{array}{l}490 \\
505\end{array}$ \\
\hline
\end{tabular}


the particular glycine pool contributing to purine synthesis has not been characterized, gross alterations in glycine metabolism might be reflected in the glycine pools contributing to the synthesis of creatinine and hippuric acid. For this reason the incorporation of glycine-1-C $\mathrm{C}^{14}$ into the urinary hippurate and creatinine of gouty and nongouty subjects was determined (Table III). In both groups of subjects a considerable range of variation was found, and no distinct pattern characteristic of the gouty subjects was discernible. The high specific activity in the early hippuric acid samples of Patient E.H. may have had some bearing on his increased incorporation of glycine$1-C^{14}$ into uric acid noted in the repeat study.

Role of uricolysis as a cause of hyperuricemia. Since excessive uric acid production cannot be demonstrated in all gouty patients, other mechanisms for the production of hyperuricemia must be considered. The proposal that a decrease in uricolysis could account for the hyperuricemia of gout (21) has received no further support in experimental work so far reported or in the present studies. The gouty subjects with normal uric acid production showed no decrease in extrarenal disposal of uric acid as compared with the control subjects (Figure 5). Present indications are that uricolysis is the result of bacterial action on uric acid contained in the gastrointestinal secretions (22). Although examples of complete recovery of injected isotopically labeled uric acid have been reported $(3,18)$, and we have noted two cases (one associated with the use of antibiotics), the relative infrequency of such diminished uricolysis and its inconstancy argue against its being a significant cause of hyperuricemia. Since the salivary excretion of uric acid is increased with the elevation of serum urate levels (22), the gouty subject should show, if anything, an increase in intestinal uricolysis.

Renal basis for hyperuricemia. These considerations leave by exclusion the suggestion that the hyperuricemia of those gouty patients who show no overproduction of uric acid may be the result of a reduced capacity to excrete uric acid. Some recent experimental evidence in support of this concept has come from the work of Nugent and Tyler (23) and from this laboratory (24).

Certain drugs, such as chlorothiazide $(25,26)$, hydrochlorothiazide (27), and pyrazinamide (28, 29 ), can cause urate retention and even gout in subjects with no pre-existing gout or hyperuricemia. The action of these drugs not only provides a model for a possible renal basis of hyperuricemia, but also suggests a new etiological classification of drug-induced secondary gout. Urate retention after muscular exercise and in toxemia of pregnancy has been attributed to the increased amounts of lactic acid produced under these circumstances $(30,31)$. It is conceivable that other metabolites having similar urate-retaining properties could be endogenously produced and thereby induce a renal basis for hyperuricemia. At the present time there has been no evidence presented for the presence of such a urate-retaining substance in the urine or body fluids of those gouty patients who have failed to produce excessive amounts of uric acid. The infrequent occurrence of clinical gout with the hyperuricemia of chronic renal disease as well as the absence of joint symptoms among the majority of hyperuricemic relatives of gouty patients, however, is evidence that factors in addition to an elevated serum urate level are involved in the genesis of acute gouty arthritis.

It seems unlikely that any single inherited disturbance of purine metabolism common to all gouty subjects would explain both an increased and a normal uric acid production. It may be more useful at this time to consider the hyperuricemia of gout to be the result of a variety of metabolic and physiological disturbances.

\section{SUM MARY}

Uric acid production has been assessed in normal, gouty, and hyperuricemic subjects by measuring the incorporation of isotopically labeled glycine into urinary uric acid and correcting such data for the disposition of the body's urate pool as determined by the simultaneous administration of isotopically labeled uric acid.

1. Nine of 14 patients with primary gout, 1 patient with gout secondary to polycythemia vera, and 1 of 3 patients with essential hyperuricemia showed excessive glycine incorporation by our criteria, although the degree of such excessive incorporation varied greatly. All patients who ex- 
creted over $600 \mathrm{mg}$ of uric acid in their urine per day while on a purine-free diet demonstrated excessive glycine incorporation.

2. The magnitude of the extra-renal disposition of uric acid varied considerably from one patient to another and masked excessive glycine incorporation into urinary uric acid in 3 patients.

3 . There remained 5 gouty patients in whom no evidence of excessive uric acid production could be found. Both the extent of glycine incorporation and the independent parameter of urate turnover values were in the normal range.

4. No evidence of a decreased uricolysis to account for hyperuricemia was found in this group of gouty patients.

These results indicate that the hyperuricemia of gout may be the result of a variety of metabolic and physiological disturbances. Such a hyperuricemia seems to be a necessary but not a sufficient condition for the subsequent development of gouty arthritis.

\section{ACKNOWLEDGMENT}

The authors wish to express their appreciation to Dr. DeWitt Stetten, Jr., for his continued interest and helpful discussions, to Mrs. Ethel Love and Mrs. Dolores Anderson for technical assistance, and to $\mathrm{Mr}$. William Comstock for the $\mathrm{N}^{15}$ determinations.

\section{REFERENCES}

1. Garrod, A. E. The Inborn Factors in Disease. Oxford, Clarendon Press, 1931.

2. Benedict, J. D., Forsham, P. H., and Stetten, DeW., Jr. The metabolism of uric acid in the normal and gouty human studied with the aid of isotopic uric acid. J. biol. Chem. 1949, 181, 183.

3. Bishop, C., Garner, W., and Talbott, J. H. Pool size, turnover rate, and rapidity of equilibration of injected isotopic uric acid in normal and pathological subjects. J. clin. Invest. 1951, 30, 879.

4. Benedict, J D., Roche, M., Yü, T. F., Bien, E. J., Gutman, A. B., and Stetten, DeW., Jr. Incorporation of glycine nitrogen into uric acid in normal and gouty man. Metabolism 1952, 1, 3.

5. Benedict, J. D., Yü, T. F., Bien, E. J., Gutman, A. B., and Stetten, DeW., Jr. A further study of the utilization of dietary glycine nitrogen for uric acid synthesis in gout. J. clin. Invest. 1953, 32, 775.

6. Wyngaarden, J. B. Overproduction of uric acid as the cause of hyperuricemia in primary gout. J. clin. Invest. 1957, 36, 1508.

7. Seegmiller, J. E., Laster, L., and Liddle, L. V. Failure to detect consistent overincorporation of glycine-1- $\mathrm{C}^{14}$ into uric acid in primary gout. Metabolism 1958, 7, 376.

8. Wyngaarden, J. B. Normal glycine-C $\mathrm{C}^{14}$-incorporation into uric acid in primary gout. Metabolism 1958, 7, 374.

9. Gutman, A. B., Yü, T. F., Black, H., Yalow, R. S., and Berson, $S$. A. Incorporation of glycine-1-C ${ }^{14}$, glycine-2- $\mathrm{C}^{14}$ and glycine- $\mathrm{N}^{15}$ into uric acid in normal and gouty subjects. Amer. J. Med. 1958, 25, 917.

10. Schoenheimer, R., and Ratner, S. Studies in protein metabolism. III. Synthesis of amino acids containing isotopic nitrogen. J. biol. Chem. 1939, $127,301$.

11. Muller, A. F., and Bauer, W. Uric acid production in normal and gouty subjects, determined by $\mathrm{N}^{16}$ labeled glycine. Proc. Soc. exp. Biol. (N. Y.) 1953, 82, 47.

12. Cavalieri, L. F., Blair, V. E., and Brown, G. B. The synthesis of uric acid containing isotopic nitrogen. J. Amer. chem. Soc. 1948, 70, 1240.

13. Liddle, L., Seegmiller, J. E., and Laster, L. The enzymatic spectrophotometric method for determination of uric acid. J. Lab. clin. Med. 1959, 54, 903.

14. Benedict, S. R. Studies in creatine and creatinine metabolism. I. The preparation of creatine and creatinine from urine. J. biol. Chem. 1914, 18, 183.

15. Grayzel, A. I., Seegmiller, J. E., and Love, E. Suppression of uric acid synthesis in the gouty human by the use of 6-diazo-5-oxo-L-norleucine. J. clin. Invest. 1960, 39, 447.

16. Gutman, A. B., and Y $\ddot{u}, T$. F. Renal function in gout, with a commentary on the renal regulation of urate excretion, and the role of the kidney in the pathogenesis of gout. Amer. J. Med. 1957, 23, 600.

17. Benedict, J. D., Forsham, P. H., Roche, M., Soloway, S., and Stetten, DeW., Jr. The effect of salicylates and adrenocorticotropic hormone upon the miscible pool of uric acid in gout. J. clin. Invest. 1950, 29, 1104.

18. Eisen, A., and Seegmiller, J. E. Uric acid metabolism in psoriasis. J. clin. Invest. 1961, 40, (Aug.).

19. Benedict, J. D., Kalinsky, H. J., Scarrone, L. A., Wertheim, A. R., and Stetten, DeW., Jr. The origin of urinary creatine in progressive muscular dystrophy. J. clin. Invest. 1955, 34, 141.

20. Watts, R. W. E., and Crawhall, J. C. The first glycine metabolic pool in man. Biochem. J. 1959, 73, 277.

21. Bien, E. J., and Zucker, M. Uricolysis in normal and gouty individuals. Ann. rheum. Dis. 1955, 14, 409.

22. Sorensen, L. B. Degradation of uric acid in man. Metabolism 1959, 8, 687.

23. Nugent, C. A., and Tyler, F. H. The renal excretion of uric acid in patients with gout and in nongouty subjects. J. clin. Invest. 1959, 38, 1890. 
24. Seegmiller, J. E., Grayzel, A., and Plato, C. Renal excretion of uric acid in gout. In preparation.

25. Oren, B. G., Rich, M., and Belle, M. S. Chlorothiazide (Diuril) as a hyperuricacidemic agent. J. Amer. med. Ass. 1958, 168, 2128.

26. Aronoff, A. Acute gouty arthritis precipitated by chlorothiazide. New Engl. J. Med. 1960, 262, 767.

27. Healey, L. A., Magid, G. J., and Decker, J. L. Uric acid retention due to hydrochlorothiazide. New Engl. J. Med. 1959, 261, 1358.

28. Cullen, J. H., LeVine, M., and Fiore, J. M. Studies of hyperuricemia producted by pyrazinimide. Amer. J. Med. 1957, 23, 587.

29. Shapiro, M., and Hyde, L. Hyperuricemia due to pyrazinamide. Amer. J. Med. 1957, 23, 596.

30. Yü, T. F., Sirota, J. H., Berger, L., Halpern, M., and Gutman, A. B. Effect of sodium lactate infusion on urate clearance in man. Proc. Soc. exp. Biol. (N. Y.) 1957, 96, 809.

31. Handler, J. S. The role of lactic acid in the reduced excretion of uric acid in toxemia of pregnancy. J. clin. Invest. 1960, 39, 1526. 